\title{
DO PORTUGUÊS AO ESPANHOL: UM ESTUDO SOBRE O USO DO PERFEITO COMPOSTO POR BRASILEIROS APRENDIZES DE E/LE
}

\author{
DEL PORTUGUÉS AL ESPAÑOL: UN ESTUDIO SOBRE EL USO DEL \\ PERFECTO COMPUESTO POR BRASILEÑOS APRENDIENTES DE E/LE
} FROM PORTUGUESE TO SPANISH: A STUDY ON THE USE OF THE
PERFECT BY BRAZILIAN LEARNERS OF E/LE

\author{
Carolina Salvino CORREA ${ }^{1}$ \\ Leandro Silveira de ARAUJO ${ }^{2}$
}

RESUMO: O presente trabalho procurou analisar o funcionamento do português e do espanhol no que se refere ao uso do perfeito composto, observando pontos de encontro e de divergência entre as línguas, isso para compreender, por meio de uma análise contrastiva, o uso que o aprendiz faz da língua estrangeira. Somaram-se aos trabalhos, leituras e discussões em torno de questões que abordam o tema em foco, tais como o conceito de "interlíngua" e "transferência", "temporalidade verbal" nas línguas portuguesa e espanhola, entre outros. Como corpus de análise, observamos áudios transcritos produzidos por alunos do curso de Letras: Espanhol do quarto período (nível intermediário). Recorremos ao software Antconc, para proceder ao exame do material disponível. Como resultado, foi visto que não há interferência semântica significativa da língua materna sobre esse assunto, mas ocorrem outros tipos de fenômenos, como a generalização de traços semânticos e morfológicos.

PALAVRAS-CHAVE: Perfeito. Análise contrastiva. Interlíngua. Tempo verbal.

RESUMEN: Este estudio tiene como objetivo analizar el funcionamiento del portugués $y$ del español en cuanto al uso del perfecto compuesto, observando los puntos de encuentro y divergencia entre las lenguas; para ello, se hace un análisis contrastivo para averiguar el uso que hace el aprendiente de la lengua extranjera. Se añadieron al trabajo lecturas y discusiones en torno a asuntos que tienen que ver con la temática enfocada como el concepto de "interlengua" y "transferencia", " temporalidad verbal" en portugués y español, entre otros. Como corpus de análisis, observamos audios transcritos producidos por alumnos de la carrera de Letras: Español del cuarto curso (nivel intermedio). Hemos recurrido al software Antconc para proceder al examen del material disponible. Como resultado se ha visto que no hay interferencia semántica significativa de la lengua materna sobre este tema, pero ocurren otros tipos de fenómenos, como la generalización de rasgos semánticos y morfológicos.

PALABRAS CLAVE: Perfecto. Análisis contrastivo. Interlengua. Tiempo verbal.

${ }^{1}$ Universidade Federal de Uberlândia (UFU), Uberlândia - MG - Brasil. Graduada em Letras. Instituto de Letras e Linguística. E-mail: loracsc19@ gmail.com

${ }^{2}$ Universidade Federal de Uberlândia (UFU), Uberlândia - MG - Brasil. Professor Adjunto. Instituto de Letras e Linguística. E-mail: araujoleandrosilveira@gmail.com 
ABSTRACT: This paper analyzes the functioning of Portuguese and Spanish regarding the use of the perfect tense, observing the similarities and divergences between these languages, trying to understand, through a contrastive analysis, the use of the foreign language by the learner. Adding to the work, we looked for texts and discussions about issues that address the topic in focus, such as the concept of "Interlingua" and "transference", "tense" in the Portuguese language and the Spanish language, among others. As a corpus of analysis, we observed transcribed audios produced by students of 4th period of the Spanish undergraduate course (intermediate level). We have resorted to the Antconc software to examine the available material. As a result, it has been seen that there is no significant semantic interference from the mother tongue on this subject, but other types of phenomena occur, such as the generalization of semantic and morphological traits.

KEYWORDS: Perfect. Contrastive Analysis. Interlingua. Tense.

\section{Introdução}

Neste artigo, objetivamos descrever e analisar o uso do Pretérito Perfecto Compuesto (PPC - "he estudiado") realizado por estudantes de espanhol como língua estrangeira (E/LE) do curso de Letras de uma universidade pública brasileira. Dados que nos permitiram refletir sobre algumas dificuldades enfrentadas durante o processo de aprendizagem de E/LE. Para isso, descrevemos o funcionamento desse tempo verbal nas línguas espanhola e portuguesa e, diante dos resultados do estudo desse contraste, avaliamos as possíveis dificuldades que o brasileiro poderia encontrar ao aprender a língua espanhola e quais os motivos que o levariam a tais dificuldades.

Como nosso estudo parte de uma análise contrastiva que visa compreender o uso que o aprendiz faz da língua estrangeira (LE), somaram-se aos trabalhos, leituras e discussões entorno de questões que abordam o tema em foco, tais como o conceito de "interlíngua" e "transferência" (BARALO OTTONELLO, 2004; DURÃO, 2007), "análise contrastiva" (BARROS, 2005, DURÃO 2007), "temporalidade verbal" nas línguas portuguesa (ILARI, 2001; BARBOSA, 2008; CASTILHO, 1966) e espanhola (CARTAGENA, 1999, FERREIRA, 2010; ARAUJO, 2012, 2013), entre outros.

A fim de proceder à análise dos dados, recorremos a um corpus oral, no qual se encontram enunciados produzidos por graduandos do quarto período do curso de LetrasEspanhol - formação que potencialmente confere ao aluno um nível intermediário de domínio da língua espanhola. Em complemento, a preferência pelo público se deve ao fato de que, geralmente nesse estágio de formação, os alunos têm uma maior exposição, reflexão metalinguística e oportunidade para produzir textos em que se utiliza 
sistematicamente o perfecto compuesto. Considerando esse contato é que analisaremos a interlíngua desses aprendizes e as principais dificuldades decorrentes do processo de aprendizagem de E/LE. Em outras palavras, interessa-nos saber se, de alguma maneira, o indivíduo assume como base as informações próprias de sua língua materna para lidar com o uso do PPC-Espanhol e se criar essa ponte de comparação entre os usos feitos da forma composta nos dois idiomas pode servir ao estudante como uma ferramenta de aprendizagem.

Repousa sobre esse interesse o pressuposto natural de que, no contato com uma língua estrangeira, o aprendiz procura encontrar o maior número de estruturas linguísticas parecidas com as da sua língua materna. Em seguida, conta com outras estratégias, como a repetição para memorização, comparação de frases e outras estruturas sintáticas. Na sequência, dá-se uma aproximação ao nível do sentido, valendo-se novamente do conhecimento de uso linguístico que possui previamente. É nessa última etapa que se evidenciam os contrastes de uso entre as duas línguas (BARALO OTTONELLO, 2004; DURÃO, 2007).

A razão que nos leva a estudar a interferência na aprendizagem do espanhol, mais especificamente, no uso do pretérito perfecto compuesto, deve-se aos diferentes comportamentos que a forma verbal apresenta no português e no espanhol. No português, a construção "tenho estudado" assume um valor marcadamente aspectual de duração/iteração, que permite se referir a uma situação iniciada no passado, que permanece no presente e que, supostamente, dirige-se ao futuro. Por sua vez, no espanhol, a perífrase "he estudiado", cuja origem linguística é a mesma da língua portuguesa (ARAUJO, 2017), pode desfavorecer o uso aspectual (de duração, por exemplo) passando a expressar um valor marcadamente temporal de passado, isto é, entre outras possibilidades, o perfecto compuesto refere-se a situações passadas e terminadas, não necessariamente durativas. Assim, pode-se dizer que apesar da proximidade histórica e formal que guardam as formas compostas nas duas línguas românicas (verbo auxiliar + particípio invariável), funcionalmente operam de formas particulares.

Frente à enganosa similitude formal que pode borrar inicialmente as particularidades funcionais do perfeito composto em ambas as línguas, justifica-se a necessidade desse estudo por analisar possíveis dificuldades e estratégias de aprendizagem usadas pelo aprendiz brasileiro de E/LE para lidar com o uso da forma composta na língua meta. Finalmente, alertamos que o cumprimento deste estudo 
também contribui para a desmistificação da ideia de que o espanhol é uma língua de "instantâneo" domínio para brasileiros, devido à semelhança que guarda com o português e do pensamento pré-estabelecido de que essas duas línguas se diferenciarem somente no nível lexical (como já criticaram Fanjul e González (2014), entre outros). A seguir, apresentaremos as características funcionais da forma composta nas duas línguas.

\section{O pretérito perfecto compuesto no espanhol}

De acordo com Boléo (1936), o perfecto simple (canté) e o compuesto (he cantado) são de uso corrente tanto na fala quanto na escrita, fazendo do espanhol a língua românica mais difícil de se estabelecer com precisão a diferença de emprego e de sentido entre uma forma e outra.

Em espanhol, os tempos compostos operam expressando anterioridade, coexistência ou prospectividade às formas temporais primárias de presente (canto), de pretérito (canté) ou de futuro (cantaré) (CARTAGENA, 1999). Restringindo-nos ao pretérito perfecto compuesto (PPC), em cuja composição encontra-se o verbo auxiliar "haber" conjugado no presente do indicativo junto a uma forma de particípio invariável, sabemos que fundamentalmente expressa anterioridade e "perfeição". Essa perfeição característica do PPC implica que as situações descritas pelo pretérito perfecto estão concluídas e ocorreram em uma concepção temporal ainda vigente no momento em que se enuncia. Vejamos que, em (1), ao dizer "han tirado", o enunciador não apenas informa que o lançamento de agrotóxicos já ocorreu, mas também que dada atividade ocorreu "este año", isto é, numa envoltura temporal ainda vigente quando se enuncia:

\section{(1) Este año han tirado trescientos millones de litros de agroquímicos. ${ }^{3}$}

Nos termos de Cartagena (1999, p. 2941), o PPC indica que uma ação se realizou antes da enunciação, que serve de referência para medir o tempo, mas dentro de um âmbito temporal que mantém simultaneidade com o momento de fala. Em outras palavras, o uso dessa perífrase não faz simplesmente referência a uma situação passada, mas fundamentalmente em direta relação com o ato de fala.

${ }^{3}$ Enunciado retirado de uma entrevista radiofônica difundida pela rádio Cadena 3, de Córdoba/Argentina $(13 / 06 / 2010)$. 
Segundo Araújo (2013, 2017), a norma gramatical denomina a função que descrevemos de antepresente e a atribui fundamentalmente ao Pretérito Perfeito Composto (PPC) espanhol. Isto é, recorre-se à forma composta para se referir a situações passadas que ocorrem num mesmo segmento temporal de referência em que se dá o momento de fala. A exemplo do enunciado (1), essa é a relação temporal que também observamos em (2), pois o marcador temporal ("hoy") evidencia que tanto a situação apresentada ("ha ganado") como a enunciação ocorrem no mesmo contexto temporal:

(2) La ópera prima del director indio ha ganado hoy la Butaca de oro del Premio Principado de Asturias $[. . .]^{4}$

Contudo, a partir desse valor tido como primário, desdobram-se outros sentidos secundários. Tanto é assim que o PPC é usado também para se referir a ações passadas em um período de tempo não determinado. Em outras palavras, expressa experiências passadas sem se referir a quando ocorreram. Assim, ao utilizar o PPC, o falante mais uma vez indica que determinada situação que aconteceu no passado repercute, de alguma maneira, no presente.

Por não especificar na linha do tempo exatamente o momento quando dado evento sucedeu, podemos lhe atribuir uma indeterminação temporal. Assim, em (3), apesar de não especificar quantas vezes, por quanto tempo ou em que momento exato Jorge Valentín fez suas declarações, o enunciado faz-nos saber que o entrevistado esteve em contato com o jornal 'la voz del interior' por mais de uma ocasião num passado não determinado exatamente, mas que é envolto pelo mesmo "âmbito primário de referência presente" que abrange o momento de fala. Devemos observar, ainda, que ao dizer "esta nota", delimita-se, de alguma maneira, o âmbito temporal primário no qual a situação descrita ocorreu. Ou seja, essa quantidade não explicitada de interações com o entrevistado ocorreu durante o tempo que envolveu a preparação da edição do jornal.

(3) [...] vamos a hablar ya mismo, precisamente, con Jorge Valentín que ha hecho esa y otras declaraciones para esta nota de la voz del interior. ${ }^{5}$

${ }^{4}$ Enunciado retirado da versão eletrônica do jornal espanhol El país, de 29/11/2014.

${ }^{5}$ Enunciado retirado de uma entrevista radiofônica difundida pela rádio Cadena 3, de Córdoba/Argentina $(13 / 06 / 2010)$. 
Assim, se por um lado a ausência de um delimitador temporal explícito faz-nos considerar que o evento pode ter ocorrido uma ou mais vezes no período que aparentemente envolve grande parte da vida do observador (RAE, 2009), por outro, com o uso de um especificador ("esta nota"), o momento em que o evento ocorreu é diminuído, sem, contudo, determinar exatamente quando se deu dada situação.

Para melhor entender o comportamento complexo e polissêmico dessa forma verbal, devemos considerar, entre outros, o tempo e o aspecto - duas categorias fundamentais para o estudo das formas verbais. O tempo vinculado pela forma do PPC contribui para a expressão de acontecimentos anteriores à origem, contudo, dentro de um âmbito temporal de coexistência à enunciação. Por sua vez, o valor aspectual de perfeito aponta para o momento que está imediatamente posterior ao tempo da situação descrita, mostrando, desse modo, as consequências de dado fato no momento de fala. Assim, a relevância de uma situação passada provém da observação de suas consequências (aspecto), que, como visto, são envoltas pelo mesmo âmbito de referência presente que abarca a enunciação (tempo).

Segundo Araujo $(2013,2017)$, outros valores são atribuídos eventualmente ao PPC por alguns estudos gramaticais: passado imediato, resultativo, experiência, persistência, passado absoluto, antepretérito e prospectivo. Em especial, o passado absoluto difere-se do antepresente por fazer referência a situações passadas que ocorrem fora da envoltura temporal em que o falante enuncia, tal como observamos em (4), em que a ação descrita (hemos hecho) ocorre em uma concepção temporal (domingo pasado) já concluída e anterior ao "agora" do enunciador, isto é, ao momento em que a sentença é originalmente produzida.

(4) Mi labor específica y la labor de mi grupo es llevar dignidad, por ejemplo, como lo hemos hecho el domingo pasado. ${ }^{6}$

Passemos, na próxima seção, ao estudo do perfeito composto no português.

\section{O pretérito perfeito composto no português}

No português, o perfeito composto ("tenho feito") teve o verbo auxiliar que originalmente compunha a perífrase alterado, de modo que se deixou o verbo "haver" e se assumiu o verbo "ter". Funcionalmente mais estável, a construção exprime iteração e

6 Enunciado retirado de uma entrevista radiofônica difundida pela rádio Continental, de Buenos Aires/Argentina (02/06/2010). 
continuidade. Isto é, necessariamente diz respeito a uma situação que começou no passado e que ainda permanece ocorrendo quando se enuncia. Em (5) observamos que a situação descrita (tem operado), desenvolve-se desde o passado até o momento de enunciação.

(5) Com a perda de mercado, a Petrobras tem operado suas refinarias com elevados níveis de ociosidade. ${ }^{7}$

O PPC no português é inadequado não só para descrever fatos que ocorreram uma única vez, mas também para descrever a repetição quando se quer ao mesmo tempo explicitar quantas vezes o fato se repetiu (ILARI, 2001). Nestes casos, o falante brasileiro do português recorre ao passado simples, como em (6) e (7).

(6) Comeu tudo que estava na mesa.

(7) Já refez cinco vezes o mesmo trabalho.

Castilho (1966, p. 143) distingue dois valores do perfeito composto no português, sendo um referente à ação que "dura" no passado e, outro, à ação que se "repete" no passado, estendendo-se, em ambos os casos, até o presente. Assim, o PPC expressará duração quando vinculado a um verbo atélico, ou seja, que expressa uma ação sem fim marcado (como pensar, correr, sonhar). Por sua vez, o valor de iteração ocorrerá quando o verbo principal for télico, isto é, que expressa uma ação com determinada finalidade (como espirrar, atirar, encontrar). Os enunciados ${ }^{8}$ (8) e (9) ilustram os respectivos valores:

(8) O senhor não pode calcular como essa doença tem aborrecido.

(9) Tenho perdido um dinheirão por causa dele, tu nem imaginas.

O pretérito composto, no português tem valor expressamente aspectual. Segundo Castilho (1968), o aspecto no PPC português corresponde à visão objetiva da relação entre o processo ou estado expresso pelo verbo e a ideia de duração ou desenvolvimento.

Apesar da proximidade de muitos traços linguísticos das línguas portuguesa e espanhola, no que diz respeito ao Pretérito Perfecto Compuesto, vemos que há diferenças formais e funcionais marcantes. Enquanto no português, o PPC apresenta um auxiliar com base no verbo "ter" e um valor aspectual de continuidade, no espanhol, a

\footnotetext{
${ }^{7}$ Enunciado retirado da versão eletrônica do jornal A Folha de São Paulo, de 06/03/2018.
}

${ }^{8}$ Exemplos retirados de Castilho (1966, p. 143). 
construção é formada por uma auxiliar com base no verbo "haber" e apresenta um valor sobrebujantemente temporal: de antepresente, isto é, de uma situação anterior e inserida ao marco referencial de presente - quando ocorre a enunciação.

Considerando essas particularidades, nossa hipótese de pesquisa repousa sobre o pressuposto de que o aprendiz de E/LE pode vir a resgatar a forma (auxiliar "ter") e/ou função (“duração”) do PPC de sua língua materna quando enuncia na língua espanhola. Desse modo, estaria desenvolvendo, a partir da transferência de traços linguísticos, um fenômeno característico de interlíngua. A fim de melhor avaliarmos nossa hipótese, passemos a refletir sobre interlíngua e alguns de seus fenômenos.

\section{Interlíngua e transferência}

Baralo Ottonello (2004) e Durão (2007) afirmam que a interlíngua é um fenômeno de aproximação que ocorre durante o processo de ensino-aprendizagem de uma língua estrangeira (LE). Surge como resultado das hipóteses que o aprendiz faz sobre o funcionamento da LE, com base no conhecimento que tem da própria língua materna. Torna-se mais perceptível no momento em que o aprendiz, numa determinada situação de uso oral ou escrita, mistura estruturas de sua língua materna com a da língua estrangeira, numa tentativa de se apropriar de duas línguas para poder se comunicar.

De acordo com Baralo Ottonello (2004), os estudos sobre a interlíngua tentam descobrir o que ocorre na mente do aprendiz, local de processamento de dados linguísticos. Em outras palavras, deseja-se entender o que se passa pela mente do aprendiz durante o processo de ensino-aprendizagem de uma LE e como é feita a assimilação dos sistemas linguísticos produzidos pelo aluno.

Por sua vez, Durão (2007) define a interlíngua como um sistema linguístico em construção, que está entre uma língua e outra. Sua característica principal é a transitoriedade. Por conta disso, podemos afirmar que a interlíngua é uma parte do processo de aprendizagem do estudante de LE. Neste processo, nota-se uma sucessão de fases em que o aluno começa a se desprender da língua materna, misturando-a com a língua alvo, até alcançar um estágio em que já não se percebe tão explicitamente a mescla dos dois sistemas linguísticos.

Levando em consideração o corpus analisado nesta pesquisa (produções orais em língua espanhola por alunos brasileiros de nível intermediário de conhecimento do castelhano), é possível que os aprendizes de E/LE faça uso do PPC do espanhol com 
alguma interferência da respectiva perífrase do português, já que são formas que guardam certas semelhanças. Desse modo, uma primeira transferência linguística possível seria de nível morfológico, uma vez que o aprendiz poderá usar o verbo “tener" do espanhol ao invés do "haber", por influência da perífrase de sua língua materna, em que a forma se constitui por "ter + particípio". Alguns exemplos potencialmente esperados seriam:

(10) ' Tengo dormido poco

(11) 'Ella tiene trabajado mucho esta semana

Além do nível morfológico, o aprendiz pode ainda fazer uso do PPC no espanhol de acordo com os valores semânticos usados em sua língua materna. Como os valores atribuídos ao uso do PPC na língua portuguesa é de duração ou de iteração, poderia ocorrer do aluno dar preferência ao uso da construção com esse valor, tal com o ilustra (12):

(12) 'He trabajado mucho durante estos años para llegar a esta competencia.

Conforme explica Durão (2007, p. 28), a base de aprendizagem de uma língua estrangeira consiste em que os aprendizes assimilem regras linguísticas a partir da observação de mostras da língua que têm a sua disposição. Desse modo, a partir da ação de um dispositivo mental que contém uma gramática abstrata, progressivamente vai se assumindo a forma da gramática de uma língua específica (DURÃO, 2007).

Contudo, para compreender melhor o uso de determinadas regras linguísticas da língua estrangeira, o aprendiz pode se valer da transferência de elementos da sua língua materna para a interlíngua desenvolvida por ele. Dessa forma, apropria-se de uma estratégia de aprendizagem que lhe fornece base para conhecer os pontos linguísticos semelhantes e diferentes entre sua língua materna e a língua estrangeira. Nesse sentido, a interferência da língua materna na produção em língua estrangeira não deve ser entendida como um erro, mas como uma importante estratégia de aprendizagem e de comunicação, que se torna menos recorrente à medida que o aprendiz avança na experiência e conhecimento sobre o funcionamento da língua estrangeira.

A transferência, como conceitua Durão (2007, p. 34), ocorreria quando a pessoa tenta aprender algo novo (como uma língua estrangeira) tratando de equiparar esse novo conhecimento com algo que já domina. Para Baralo Ottonello (2004, p. 376) seria um mecanismo cognitivo subjacente à aquisição de L2. Desse modo, é possível pensar a 
transferência como o conhecimento que o aluno possui referente à sua língua materna sendo transferido para o momento de aprendizagem da LE, quando ocorre o fenômeno de interlíngua.

Frente a tudo isso, fica claro que a interlíngua desenvolvida pelo aprendiz contribui para sua compreensão do funcionamento, por exemplo, de determinada regra gramatical da LE. Assim, ao aprender os tempos verbais, o aprendiz poderá observar o comportamento de uso dessa estrutura em sua língua e associá-la à língua estrangeira, refletindo se a regra se aplica da mesma forma como em sua língua materna. Além de levar em consideração sua língua materna, o aprendiz pode, ainda, recorrer a determinadas regras gramaticais de outras línguas estrangeiras com que tenha contato, a fim de ver se elas se comportam ou não da mesma maneira na língua alvo. Isso posto, concluímos que a interlíngua pode se constituir de três elementos: da língua materna do aprendiz, do conhecimento prévio do aprendiz sobre outras línguas estrangeiras e da língua objeto de estudo (DURÃO, 2007, p. 25).

Uma vez apresentado nosso referencial teórico, descreveremos, a seguir, o corpus utilizado para coleta de dados, bem como o modo de processá-los.

\section{Corpus e processamento de dados}

A fim de cumprir o objetivo de encontrar elementos de transferência linguística do português para o espanhol, recorremos a um corpus oral, cujos enunciadores foram alunos do curso de Letras: Espanhol, no quarto período, de uma universidade pública brasileira ${ }^{9}$. Nessa etapa de formação, os alunos já estabeleceram contato prévio com a língua por pelo menos 3 semestres, assim, espera-se que eles estejam em nível intermediário de proficiência em espanhol.

Os áudios foram divididos em quatro grupos, segundo o gênero discursivo dos enunciados: apresentação $[\mathrm{A}]$, debate $[\mathrm{DE}]$, diálogo $[\mathrm{DI}]$ e Leitura [LE]. Na Apresentação [A], há enunciados em que os alunos se apresentam, falando sobre si, sobre as expectativas para o curso etc., destaca-se ainda que não há interação com outros alunos. No Debate [DE], há a interação entre todos os alunos, de modo que cada um deles discute sobre seu posicionamento a respeito de um dado tema. No Diálogo [DI], há interação entre dois ou mais alunos, comunicando-se de acordo com

\footnotetext{
${ }^{9}$ Agradecimentos ao Prof. Dr. Ariel Novodvorski por disponibilizar o Corpus Oral de Espanhol como Língua Estrangeira (COrELE).
} 
determinada situação proposta. Por fim, a Leitura [LE] consiste na leitura individual de determinados trechos em espanhol. Para analisar o uso do pretérito perfecto compuesto, consideramos apenas produções mais espontâneas de fala, pois, assim, poderíamos buscar entender motivos que levaram o aluno a utilizar o PPC, bem como o modo de uso. Por isso, as gravações de "Leitura" foram desconsideradas neste estudo.

Para análise dos dados, recorremos ao software AntConc, uma ferramenta livre de análise de corpus que permite a concordância e análise automática de textos. A seguir, a figura 1 representa a interface do programa na seleção do auxiliar "haber" na primeira pessoa do singular ("he").

Figura 1: Palavra-chave: "he"

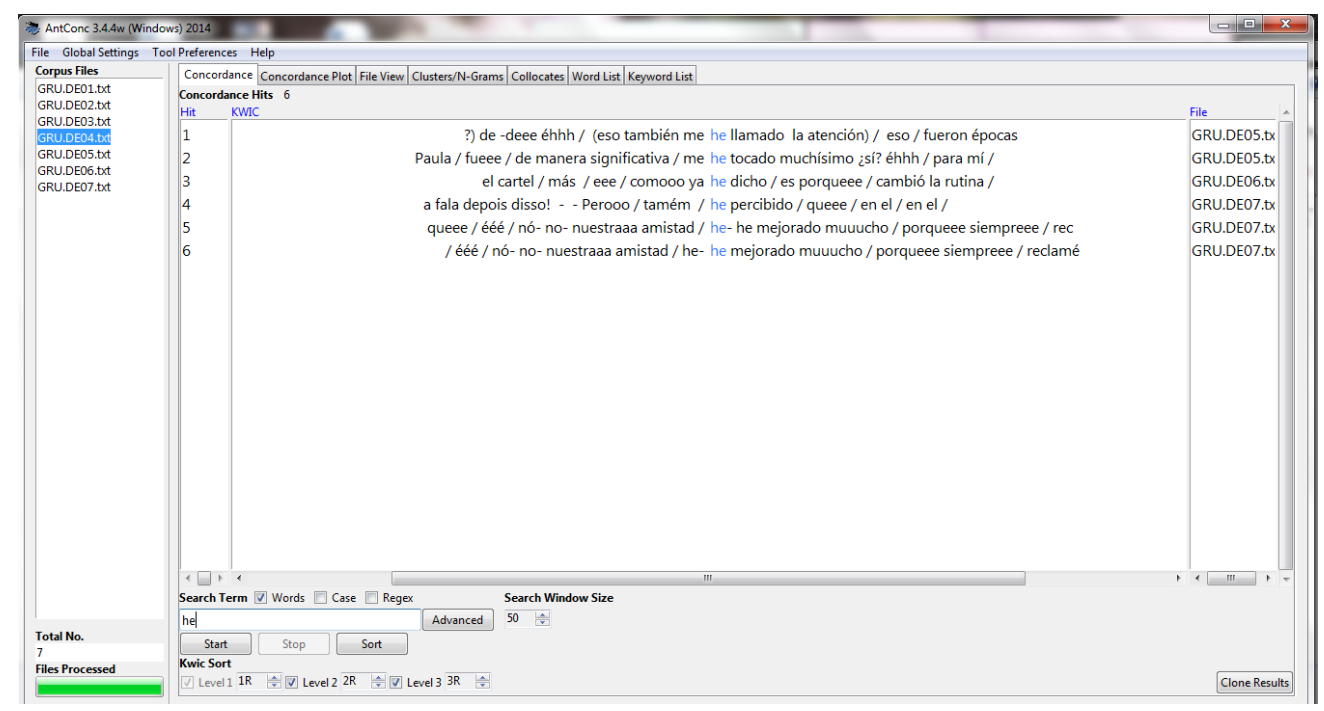

Fonte: própria.

Para encontrar os usos do PPC em espanhol no corpus, foram selecionadas e adicionadas ao software as transcrições dos áudios em formato .txt, ("File" => "Open Files"). Para realizar as buscas, utilizamos a ferramenta "Search Term" e colocamos como "palavras-chave" a conjugação do verbo haber no presente do indicativo (he, has, ha/hay, hemos, habéis, han). Essa busca é ilustrada pelas figuras 1 e 2.

Figura 2: Palavra-chave: " $h a "$ 


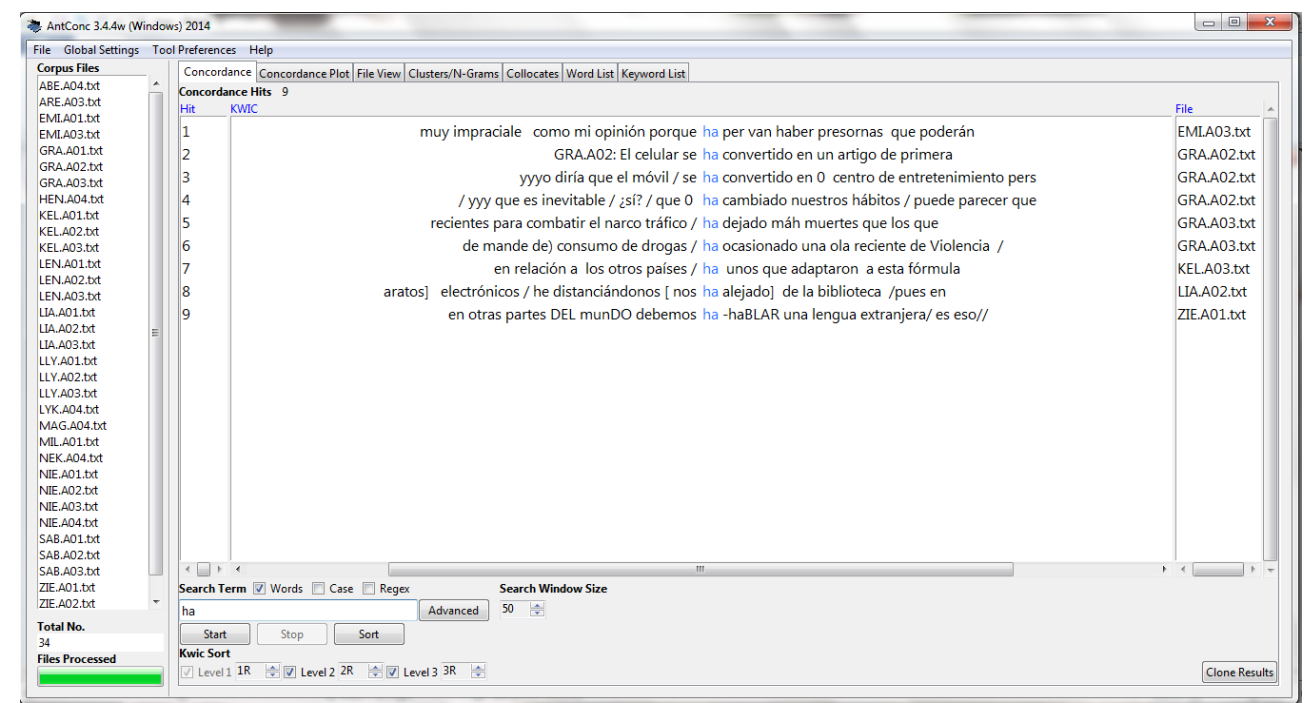

Fonte: própria.

Não foram encontrados usos nas conjugações de $2^{\mathrm{a}}$ pessoa do singular ("has"), $1^{\text {a }}$ pessoa do plural ("hemos") e $2^{\mathrm{a}}$ pessoa do plural ("habéis") em nenhum enunciado. Por sua vez, a conjugação "hay", correspondente ao valor de existência impessoal, apareceu de forma significativa seguida por um particípio, como podemos observar na Figura 3. Isso nos faz pensar que o aluno pode fazer uma espécie de confusão morfológica com elementos da língua estrangeira, generalizando o uso de uma estrutura mais corrente ("hay”) nessa língua inclusive para novos contextos.

Figura 3: Palavra-chave: "hay"

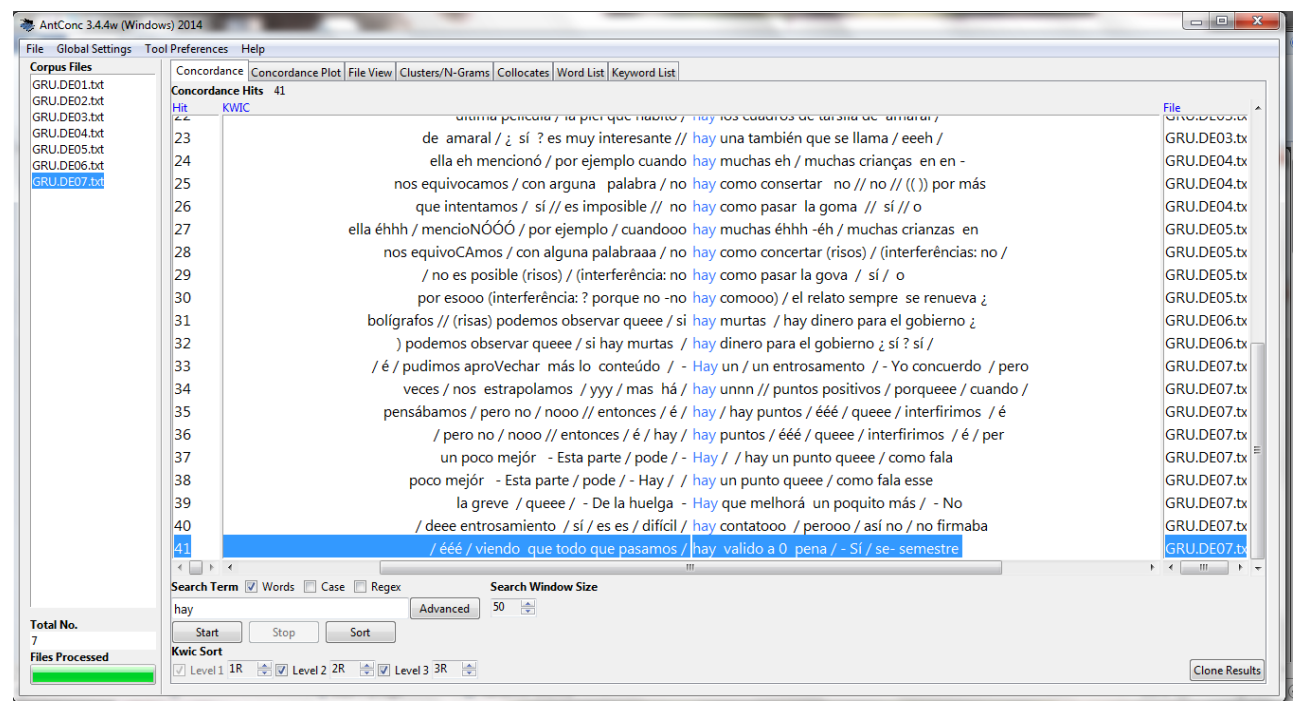

Fonte: própria

Ainda pensando em questões de interlíngua, a fim de avaliar a hipótese de que o aluno poderia formar a perífrase com o verbo "tener/ter" por transferência da estrutura em português, também fizemos uma busca pelo sufixo que indica particípio (“-ado”, “- 
edo" e "-ido"). Contudo, nenhuma associação entre o verbo "tener/ter" e um particípio foi encontrada, negando, desse modo, a hipótese de transferência morfológica da língua materna.

Por fim, alertamos que a interface do software apresenta os resultados da pesquisa por palavras-chave destacados e centralizados no quadro maior, bem como algumas palavras anteriores e posteriores à palavra indicada para a busca (destacada em azul). Para ter acesso ao enunciado completo, podemos clicar em cima da frase. Essa possibilidade investigativa permite a análise da função que cada emprego da forma composta apresentou.

Desse modo, o Software AntConc permitiu-nos analisar a morfologia, as funções e as variações no uso do PPC na fala do aprendiz brasileiro de espanhol. Favorecendo, desse modo, a análise das hipóteses de transferência e interlíngua propostas inicialmente por esse trabalho.

\section{Análise dos dados}

Foram analisados 44 áudios de alunos brasileiros do curso de graduação em Letras: Espanhol de uma universidade pública brasileira, sendo 34 apresentações [A], 03 diálogos [DI] e 07 debates [DE]. A intenção foi procurar e analisar todas as ocorrências de PPC enunciadas pelos alunos, a fim de refletir sobre cada uso baseando-se nos valores desse tempo verbal no espanhol e no português. Como visto, o objetivo fundamental foi verificar se o estudante de E/LE, de nível intermediário de proficiência linguística, apropria-se de alguma maneira das características linguísticas do PPC de sua língua materna quando faz uso do espanhol.

Foram encontradas 28 ocorrências da forma composta em todo o corpus de análise. O gráfico que segue organiza como se deu o emprego de cada uma das formas tendo em vista os valores temporais que expressa. Assim, foram identificadas 20 ocorrências $(71 \%)$ de PPC expressado antepresente e 8 casos $(29 \%)$ com valor de passado absoluto.

Gráfico 1: Resultado dos valores de usos do PPC feito por estudantes de E/LE 


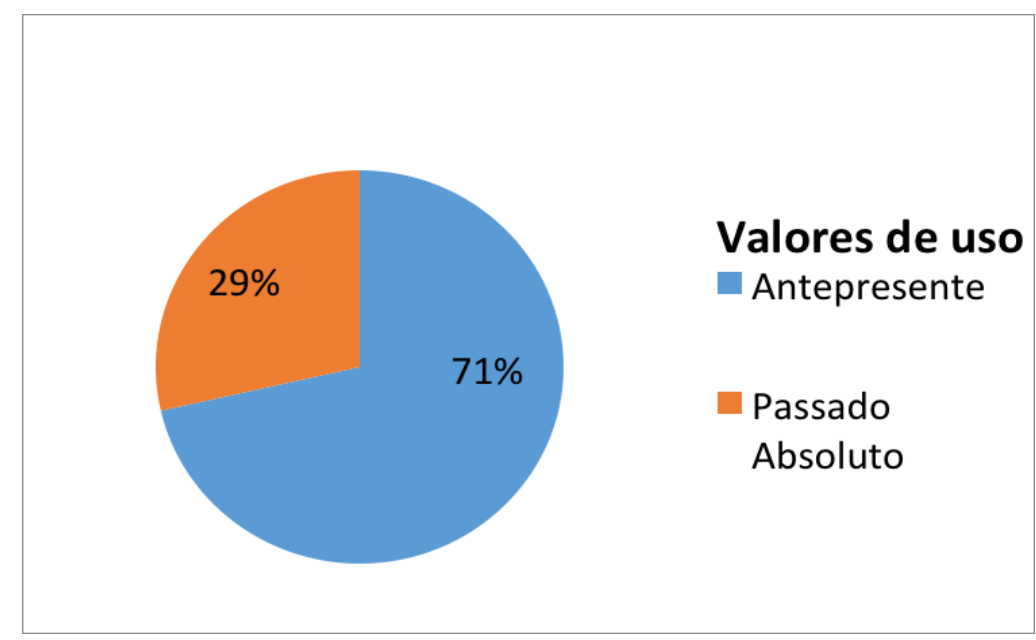

Fonte: própria

Como visto, o valor de antepresente apresentou maior recorrência junto ao emprego da forma composta pelos estudantes de E/LE, aparecendo em mais da metade das ocorrências. Esse uso pode ser observado nos enunciados que seguem:

(13) "Pero yo llego al final desta clase viendo que todo que pasamos hay valido a pena"

(14) “(...) este laboratorio, como las chicas han dicho [ahora], esto ayuda el trabajo"

(15) "Nuestra amistad he mejorado mucho [a lo largo del cursado], porque siempre reclamé (...)"

Os três enunciados foram coletados de debates em que os alunos avaliavam quais foram as contribuições da disciplina em que estavam matriculados para sua aprendizagem. De modo mais pontual, os enunciados (13) e (14) permitem inferir contextualmente que as situações descritas ("hay valido" "han dicho") ocorrem dentro da referência temporal que é a própria aula em que ocorre o debate, os marcadores temporais deixam isso ainda mais evidente: "al final desta clase" e "ahora". Em (15), também proferido durante o debate sobre a relação entre a disciplina e a formação dos alunos, encontramos o uso do PPC fazendo referência a uma experiência do enunciador que ocorreu supostamente em uma concepção temporal mais ampliada, que implicou todo o período de realização da disciplina (“[a lo largo del cursado]”). Em comum, portanto, observa-se que tanto a situação descrita como o momento de enunciação estão envoltos por uma mesma concepção temporal de referência ("al final desta clase", "ahora", "a lo largo del cursado"), a qual pode ser mais estendida ou menos estendida conforme os referentes descritos e as necessidades comunicativas. 
Igualmente importante de se destacar são os "desvios morfológicos" encontrados na conjugação do verbo auxiliar nos enunciados (13) e (15). Apesar da natureza diferente, isto é, enquanto na primeira vemos o uso de "hay" em lugar de "ha", na segunda, observamos o uso de "he" em lugar de "ha", parece-nos que a confusão se dá por uma generalização, posto que as formas escolhidas correspondem a estruturas mais usais nessa etapa de aprendizagem de E/LE. Outros casos do uso do PPC com valor de antepresente são:

(16)“Paula fue de manera significativa (...) me he tocado muchísimo ¿si?"”

(17) "yo creo que no es só por el cartel más como ya he dicho es porque cambió la rutina al amanecer de repiente las personas se deparan con un montón de policías"

Novamente encontramos a referência a situações passadas concluídas ("he tocado" e "he dicho"), mas que ocorrem em concepções temporais ainda vigente no ato da enunciação. Em (17), assume-se explicitamente o tempo presente, o recém comentado, como explicita o advérbio " $y a$ " e a situação tomada como referência: o próprio ato de fala (he dicho). Em (16), por sua vez, observa-se a relevância de uma situação passada ("he tocado") para a situação em que se encontra o enunciador no momento de fala. Novamente observamos em (16) o uso de "he" em lugar de "ha", hipoteticamente num movimento de generalização de uma forma mais usual para o aprendiz: a primeira pessoa do singular.

Contudo, há ainda um dado muito relevante apontado pelo gráfico 1 . Se por um lado, mais da metade das ocorrências de uso do PPC feita por estudantes de E/LE no corpus analisado parece estar de acordo com os valores atribuídos à língua espanhola pela norma-padrão, isto é, com valor de antepresente; por outro, observa-se um significativo uso da forma composta com o valor que denominamos de passado absoluto, isto é, $29 \%$ das ocorrências fazem referência a situações concluídas em uma referência temporal que também se encontra terminada quando ocorre o momento de fala. Alguns exemplos do uso do PPC com valor de passado absoluto retirados do corpus são:

(18) "Si recuerda de mí? Yo he venido acá la semana pasada (...)"

(19) "Bueno esta foto es una foto muy importante para mi si porque fue cuando yo he descubrido que yo tenía engresado en la UFU porque hacía un tiempo que yo ya estudiaba para intentar" 
Em (18), o marcador temporal "la semana pasada" já nos mostra que a ação ("he venido") aconteceu numa concepção temporal que começou e terminou no passado, isto é, antes da enunciação. De maneira semelhante, em (19), entende-se que a ação passada e acabada ("he descubrido" ${ }^{10}$ ) foi concluída dentro de uma referência temporal já terminada quando o falante enuncia, posto que ocorreu paralelamente a outra situação passada e concluída (ingressar à universidade).

Apesar de algumas variedades do espanhol preverem o uso do PPC com valor de passado absoluto (ARAUJO, 2013, 2017), esse uso da forma composta não é chancelado pela norma-padrão e, por conseguinte, não é contemplado nos manuais de ensino de E/LE. Frente a essa realidade, parece-nos muito pouco provável que ao fazer uso do PPC com valor de passado absoluto o aprendiz esteja explorando uma das potencialidades da língua espanhola. Parece-nos que o mais acertado é que a opção pelo perfecto compuesto possa ser uma tentativa de o aprendiz fazer referência a uma ação passada por meio da generalização do uso de uma construção mais regular que o pretérito perfecto simple - tempo que apresenta diferentes tipos de irregularidades morfológicas.

Por fim, apesar da aparente tendência a generalização do uso da forma composta para fazer referência a situações anteriores ao momento de fala, nota-se ainda um uso mais expressivo do PPC em conformidade com o ensinado através dos materiais didático de E/LE - instrumento que reflete diretamente as indicações da norma-padrão. Isso posto, parece que o conhecimento do perfeito composto em português não parece interferir fortemente no uso do PPC em espanhol (língua estrangeira).

\section{Considerações finais}

O estudo sobre a possível transferência linguística no processo de ensinoaprendizagem de E/LE nos mostrou que, no caso da forma do pretérito perfecto compuesto, o aprendiz de nível intermediário não sofre tanta interferência semântica e morfológica da língua materna, pois, de acordo com os resultados, os usos feitos pelos estudantes são parcialmente coerentes com os usos atribuídos à língua espanhola. Isto é, no nível morfológico, não foi identificado o uso do auxiliar "ter/tener" no lugar do “haver". No nível semântico, observamos um uso sobrepujante da forma composta com

${ }^{10} \mathrm{O}$ uso de "descubrido" no lugar do particípio irregular "descubierto", previsto na língua espanhola, parece resultar da generalização do processo de construção de particípios de verbos com terminação em "-ir", nos quais se permuta o morfema de infinitivo pelo sufixo "-ido". 
valor de antepresente; não identificando claramente o valor de "duração" que o aprendiz poderia transferir de sua língua materna.

De qualquer forma, a interlíngua é uma característica que certamente aparecerá em alguma parte do processo de ensino-aprendizagem de uma LE, seja no nível lexical, sintático ou semântico. Essa afirmação é possível uma vez que notamos processos de generalização morfológica e semântica em alguns usos do PPC. Esse foi o caso do uso de "hay" ou "he" no lugar da forma auxiliar de terceira pessoa do singular: "ha". Além disso, encontramos um uso significativo do PPC com valor de passado absoluto, aparentemente como resultado da generalização dessa forma verbal para se referir a situações passadas e anteriores ao momento de fala.

Por fim, é interessante perceber que, no geral, os aprendizes não apresentam maiores dificuldades ao aprender esse tempo verbal em específico, pois, de acordo com os resultados e com a norma gramatical do espanhol, os usos feitos pelos alunos aproximam-se aos valores prescritos pela norma da língua.

AGRADECIMENTOS: Agradecemos ao CNPq.

\section{REFERENCIAS}

ARAUJO, Leandro Silveira. Os valores atribuídos ao pretérito perfecto compuesto nas regiões dialetais argentinas. 2012. 212 f. Dissertação (Mestrado em Linguística e Língua Portuguesa) - Faculdade de Ciências e Letras da Universidade Estadual Paulista 'Júlio de Mesquita Filho', Araraquara, 2012.

ARAUJO, Leandro de Silveira. O pretérito em espanhol: usos e valores do perfecto compuesto nas regiões dialetais argentinas. São Paulo: Cultura Acadêmica, 2013.

ARAUJO, Leandro Silveira. A expressão dos valores "passado absoluto" e "antepresente" no espanhol: um olhar atento a variedades dialetais da Argentina e da Espanha. 2017. 410 f. Tese (Doutorado em Linguística e Língua Portuguesa) Faculdade de Ciências e Letras da Universidade Estadual Paulista 'Júlio de Mesquita Filho', Araraquara, 2017.

BARALO OTTONELLO, Marta. La interlengua del hablante no nativo. En: Sánchez Lobato, Jesus. Santos Gargallo, Isabel (Eds.). Vademécum: enseñanza y aprendizaje del español como segunda lengua y como lengua extranjera. Madrid: SGEL, 2004. p. 369-389.

BARBOSA, Juliana Bertucci. O PPC no português do Brasil e no português de Portugal contemporâneo. In: XXVI Congreso Internacional de Linguíística e Filología 
Románicas, 2008, Valencia. Actas del XXVI Congreso Internacional de Lingüística e Filología Románicas. 2008.

BARROS, Renata Maria de. La utilización del Análisis Contrastivo en la clase de gramática. In: XIII seminario de dificultades específicas en la enseñanza del español a lusohablantes, 2005, Sao Paulo. Actas del XIII seminario de dificultades específicas de la enseñanza del español a lusohablantes, 2005. p. 129-141.

BÓLEO, Manuel de Páiva. O Perfeito e o Pretérito em português em confronto com as outras línguas românicas. Coimbra; Biblioteca da Universidade. 1936.

CARTAGENA, Nelson. Los tiempos compuestos. In: BOSQUE, Ignacio; DEMONTE, Violeta. Gramática descriptiva de la lengua española. Madrid: Espasa, 1999, V.2. p. 2935-2976.

CASTILHO, Ataliba Teixeira. A sintaxe do verbo e os tempos do passado em português. ALFA, Marília, v. 9, p. 105-153, 1966.

DURÃO, Adja Balbino de Amaorin. La interlengua. Madrid: Arco Libros, 2007.

FANJUL, Adrian Pablo.; GONZALEZ, Neide T. Maia. Espanhol e português brasileiro: estudos comparados. São Paulo: Parábola Editorial, 2014.

FERREIRA, Rachel Monnier. Valores temporais-aspectuais do Pretérito Perfecto Compuesto: o caso de aprendizes falantes de Português do Brasil. In: I CIPLOM - I Congresso Internacional de Professores de Línguas Oficiais do MERCOSUL, 2010, Foz do Iguaçu. Anais do Congreso Internacional de Profesores de Lenguas Oficiales del Mercosur, 2010. v. I. p. 972-981.

ILARI, Rodolfo. Notas para uma semântica do passado composto em português.

Revista Letras, Curitiba, n. 55, p 129 - 152, 2001.

RAE. Nueva gramática de la lengua española. Madrid: Espada. 2009. 1 v.

\section{Como referenciar este artigo}

CORREA, Carolina Salvino.; ARAUJO, Leandro Silveira. Do português ao espanhol: um estudo sobre o uso do perfeito composto por brasileiros aprendizes de E/LE. Rev. EntreLínguas, Araraquara, v.4, n.1, p. 143-160, jan./jun., 2018. E-ISSN: 2447-3529. DOI: 10.29051/rel.v4.n1.2018.11198.

Submetido em: $15 / 03 / 2018$

Aprovado em: 12/04/2018 